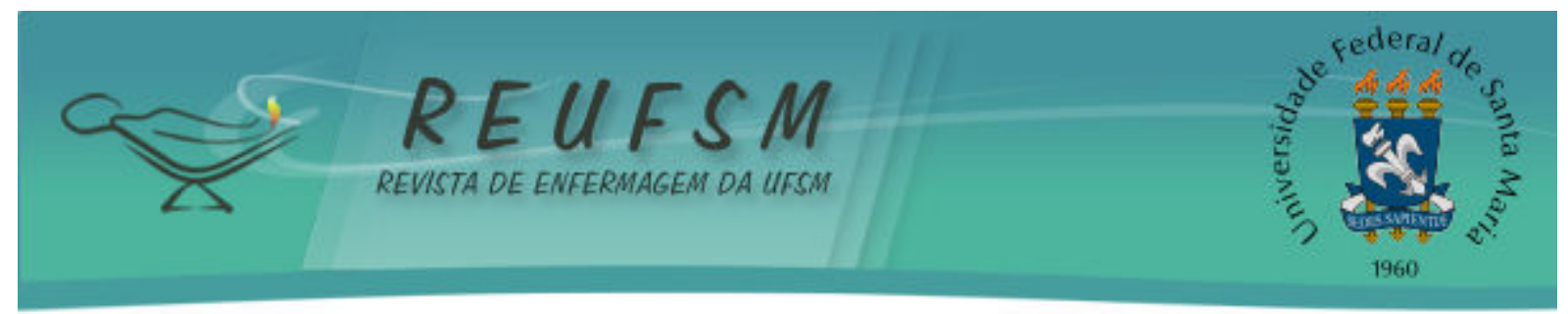

ARTIGO ORIGINAL

\title{
DOCÊNCIA UNIVERSITÁRIA E O ESTRESSE: ESTRESSORES NOS CURSOS DE ENFERMAGEM E MEDICINA
}

\section{UNIVERSITY TEACHING AND STRESS: STRESSORS IN NURSING AND MEDICINE COURSES \\ ENSEÑANZA UNIVERSITARIA Y EL ESTRÉS: FACTORES ESTRESANTES EN LOS CURSOS DE ENFERMERÍA Y MEDICINA}

\author{
Natally Pereira dos Santos ${ }^{1}$ \\ Fernanda Pereira Marinho ${ }^{2}$ \\ Kálya Yasmine Nunes de Lima ${ }^{3}$ \\ Cláudia Cristiane Filgueira Martins Rodrigues ${ }^{4}$ \\ Viviane Euzébia Pereira Santos ${ }^{5}$
}

\section{Doi: $10.5902 / 2179769217078$}

RESUMO: Objetivo: conhecer a percepção dos docentes de Enfermagem e Medicina da Universidade Federal do Rio Grande do Norte quanto aos estressores do ambiente ocupacional. Método: estudo exploratório, descritivo, com abordagem qualitativa, realizado com 21 docentes. A coleta de dados foi realizada entre abril de 2012 e fevereiro de 2013, por meio de entrevista semiestruturada. A análise de dados seguiu a técnica de análise de conteúdo. Resultados: formulou-se as seguintes categorias: 0 estresse no cotidiano docente; 0 estresse no corpo dos docentes. Conclusão: a partir dos estressores encontrados, conclui-se que é necessário cuidar da saúde física e mental destes docentes, a fim de evitar complicações tanto individuais quanto organizacionais.

Descritores: Estresse profissional; Docentes; Enfermagem; Medicina; Saúde ocupacional.

ABSTRACT: Aim: to understand faculty members of Nursing and Medicine courses from Federal University of Rio Grande do Norte (UFRN)'s perception about the workplace stressors. Method: exploratory, descriptive study with qualitative approach, conducted with 21 teachers. Data collection was conducted between April 2012 and February 2013 using a semi-structured interview. Data analysis followed the technique of content analysis. Results: The following categories emerged: Stress in everyday teaching; Stress in the body of teachers. Conclusions: According to the found stressors, it is possible to conclude that is necessary to take care of the physical and mental health of these teachers in order to avoid both individual and organizational complications.

Descriptors: Professional Burnout; Faculty; Nursing; Medicine; Occupational Health

RESUMEN: Objetivo: conocer la percepción de los docentes de Enfermería y Medicina de la Universidad Federal de Río Grande del Norte (UFRN) y los factores de estrés en el

\footnotetext{
${ }^{1}$ Enfermeira, Universidade Federal do Rio Grande do Norte, Natal-RN, Brasil. Email: natally_pereira_23@hotmail.com

${ }^{2}$ Enfermeira, Universidade Federal do Rio Grande do Norte, Natal-RN, Brasil. Email: nanamarinho_15@hotmail.com

${ }^{3}$ Enfermeira, Mestre em enfermagem, Universidade Federal do Rio Grande do Norte, Natal-RN, Brasil. Email: Yasmine.lima@hotmail.com

${ }^{4}$ Doutoranda em enfermagem pelo Programa de pós-graduação em enfermagem da Universidade Federal do Rio Grande do Norte. Professora da escola de Saúde da UFRN (ESUFRN). Membro do grupo de pesquisa: Laboratório de Investigação do cuidado, segurança, tecnologias e enfermagem da UFRN. Natal-RN. Brasil. Email: claudiacrisfm@yahoo.com.br

${ }^{5}$ Doutora em enfermagem. Professora adjunto do Departamento de Enfermagem da UFRN. Líder do grupo de pesquisa Laboratório de Investigação do cuidado, segurança, tecnologias e enfermagem da UFRN. Natal-RN. Brasil. Email: vivianeepsantos@gmail.com
} 


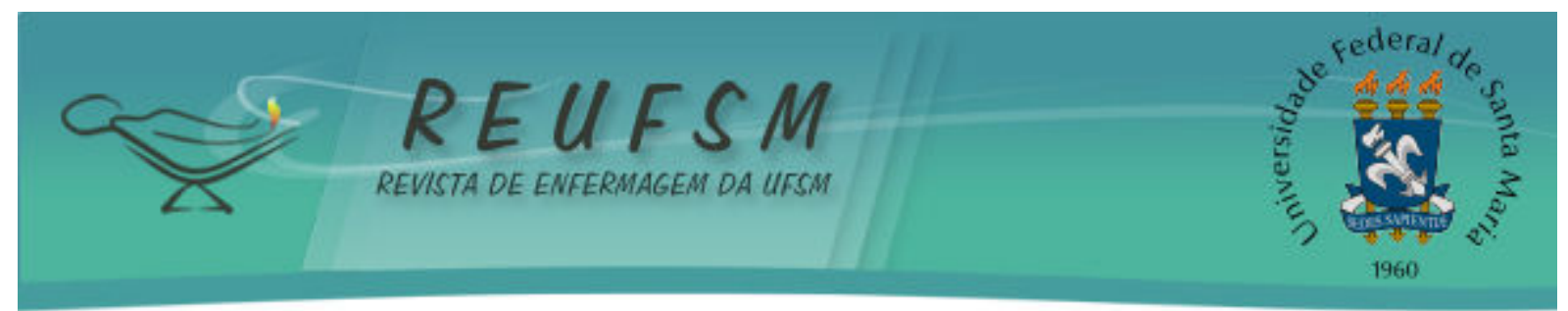

trabajo. Método: estudio exploratorio, descriptivo, con abordaje cualitativo, realizado con 21 profesores. La recogida de datos se llevó a cabo entre abril de 2012 y febrero de 2013, a través de una entrevista semiestructurada. El análisis de los datos siguió la técnica de análisis de contenido. Resultados: las siguientes categorías fueron formuladas: el estrés en la enseñanza cotidiana; El estrés en el cuerpo de profesores. Conclusiones: a partir de los factores de estrés encontrados, se concluye que es necesario cuidar de la salud física y mental de estos maestros con el fin de evitar complicaciones tanto individuales como institucionales.

Descriptores: Agotamiento Profesional; Docentes; Enfermería; Medicina; Salud Laboral.

\section{INTRODUÇÃO}

Apesar de comumente associado a algo prejudicial, o estresse em seu modelo interacionista, constitui uma reação orgânica indispensável para o equilíbrio homeostático e manutenção das atividades humanas, desde que em concentrações aceitáveis aos níveis de cortisol, hormônio marcador do estresse. ${ }^{1}$ Quando em excesso, resulta em um processo patológico, a exemplo do estresse ocupacional.

0 estresse é descrito por meio das reações físicas, mentais e emocionais desencadeadas quando as demandas exigidas de um trabalhador superam os recursos que disponibiliza para realizá-las. Como sugere o próprio nome, seu desenvolvimento está pautado nos fenômenos, relações e necessidades laborais. ${ }^{2}$ A maturidade do indivíduo, capacidade de ajuste e a resposta a estímulos estressores são importantes para definir o que pode levar a um quadro de estresse crônico. ${ }^{3}$

As diversas atribuições do cotidiano laboral expõem os profissionais a fatores precursores e/ou potencializadores do estresse com base na resposta de cada indivíduo. Neste sentido, o ambiente de trabalho do docente é permeado pela complexidade de atividades, tensão emocional, atribuições específicas do processo de ensino-aprendizagem, cansaço físico e mental, fatores estes que contribuem para o desencadeamento do estresse profissional, o que pode afetar o ambiente educacional e interferir nos objetivos pedagógicos. ${ }^{4-5}$

O mesmo pode ser aplicado aos docentes profissionais da saúde, em especial os de Enfermagem e de Medicina, que convivem com situações tais como o tipo de ambiente, a autonomia profissional, a alta responsabilidade, o contato constante com os pacientes, a complexidade das relações e a exigência quanto às competências e habilidades. ${ }^{5-6}$ Tais condições podem ser percebidas como estressoras.

Há ainda o fato de conviver com problemas estruturais como falta de material básico, infraestrutura inadequada, alta demanda de atividades, entre outros, o que aponta para a importância da realização de estudos direcionados a esse grupo de trabalhadores. Estes fatores podem ser potenciais estressores e contribuírem com o baixo desempenho, aumento da rotatividade, absenteísmo e dificuldade em se relacionar com os demais profissionais. ${ }^{5-6}$

Assim, esse estudo traz como questão de pesquisa: Quais aspectos ocupacionais são percebidos como estressores pelos docentes dos cursos de Enfermagem e Medicina da Universidade Federal do Rio Grande do Norte (UFRN)?

Diante do exposto, a pesquisa visa contribuir para que os docentes possam identificar em sua rotina fatores estressantes e a repercussão destes em seu cotidiano de trabalho, para que assim possam definir estratégias de enfrentamento adequadas e ter uma melhor qualidade de vida em seu ambiente profissional. 


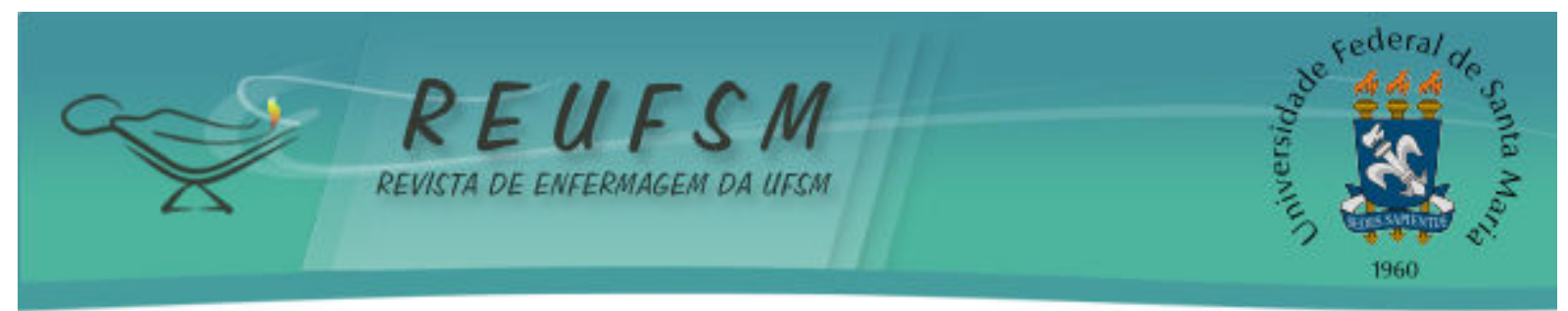

Ao se considerar esses aspectos, o estudo foi desenvolvido com o objetivo de conhecer a percepção dos docentes de Enfermagem e Medicina da UFRN, quanto aos estressores do ambiente ocupacional.

\section{MÉTODO}

O presente estudo corresponde a um recorte de uma pesquisa de caráter exploratória, descritiva e com abordagem qualitativa, intitulada "Síndrome de Burnout em docentes do Centro de Ciências da Saúde da UFRN".

A população envolveu docentes dos cursos de Enfermagem e Medicina da UFRN, com caráter efetivo e que trabalhavam em regime de 20 horas, 40 horas semanais ou dedicação exclusiva. Para seleção dos participantes, foram adotados como critérios de inclusão: ser docente efetivo da instituição, não estar em férias ou afastado do serviço e possuir pelo menos seis meses de trabalho.

Com base nos critérios estabelecidos, participaram do estudo 21 docentes, alocados nos departamentos de Enfermagem, Cirurgia, Infectologia, Medicina Clínica, Medicina Integrada, Pediatria, Saúde Coletiva e Tocoginecologia. No que se refere a distribuição por departamento, foram entrevistados sete professores de Enfermagem e 14 professores de Medicina.

A coleta de dados foi realizada entre os meses de abril de 2012 e fevereiro de 2013, sendo utilizada uma entrevista semiestruturada com os seguintes questionamentos acerca do estresse decorrente da prática docente: descreva suas atividades como docente em uma semana normal de trabalho; o que considera mais desgastante em sala de aula?; E em aulas práticas ou estágio supervisionado?; Como você observa o relacionamento interpessoal na docência?; O que você costuma fazer quando não está realizando as atividades de docência?.

Afim de garantir a fidedignidade no momento do término da coleta dessas informações, foram utilizados como critérios de saturação dos dados a integração destes com a literatura específica do tema, o estresse docente, e a sensibilidade teórica de quem analisa os dados e do próprio coletador. ${ }^{7}$

Todo material empírico coletado nas entrevistas foi codificado para assegurar o anonimato dos participantes da pesquisa. As falas foram identificadas pelas iniciais "DE" quando docentes de enfermagem, e "DM" para docentes de medicina, seguidas de números cardinais, em ordem cronológica das entrevistas.

$O$ estudo seguiu as recomendações éticas estabelecidas na Resolução $n^{\circ}$ 466/2012 do Conselho Nacional de Saúde. ${ }^{8} 0$ projeto foi submetido e aprovado pelo Comitê de Ética em Pesquisa da UFRN, obtendo-se aprovação sob protocolo de número 0287.0.51.000-11.

O material apreendido na entrevista semiestruturada foi agrupado e analisado mediante a técnica de análise de conteúdo. Este tipo de análise apresenta três fases, são elas: pré-análise, quando é realizada a leitura flutuante do material, escolha dos documentos, formulação de hipóteses e objetivos; a exploração do material, fase de descrição analítica, agregando os dados brutos em categorias temáticas; e, por último, o tratamento e interpretação dos resultados através de análise reflexiva e crítica. ${ }^{9}$

\section{RESULTADOS E DISCUSSÃO}

Com base na coleta de dados, foi possível caracterizar os participantes da seguinte forma: a maioria dos docentes é do sexo masculino (13), casados (17), acima de 40 anos (14), com mais de 10 anos de formação (17), com doutorado (10), em regime de dedicação exclusiva (11), e ministram aulas, tanto na graduação quanto na pós-graduação (12). 


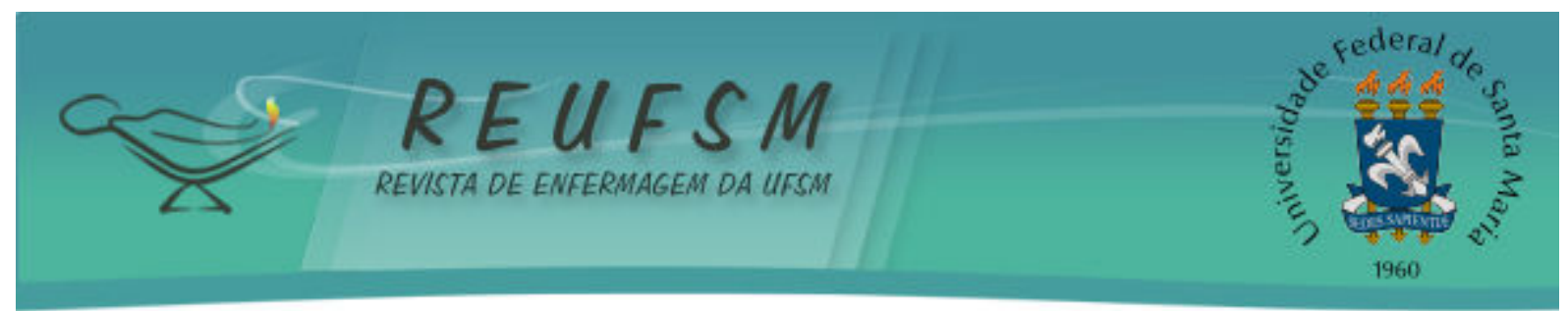

A análise do material possibilitou a formulação das categorias a seguir. Categoria 1: 0 estresse no cotidiano docente, apresentando como subcategorias: a) Prazer e estresse na docência: teoria e prática com alunos e b) A realidade do serviço enquanto um desafio; Categoria 2: 0 estresse no corpo dos docentes, com as subcategorias: a) Reflexos físicos do estresse e b) Desgaste emocional e responsabilidade profissional.

\section{0 estresse no cotidiano docente}

Esta categoria revela o quanto os professores são afetados pelo estresse e as diferenças em relação à vivência dos docentes de Enfermagem e Medicina.

\section{Prazer e estresse na docência: teoria e prática com alunos}

As aulas teórico-práticas dos docentes podem ser fontes de estresse ou prazer. Conforme os professores do Departamento de Enfermagem, os momentos em sala de aula não foram comumente descritos como prazerosos, apesar disso, o Docente 2 traz em sua fala:

em sala de aula, eu não acho que é desgastante, porque é uma coisa que eu gosto de fazer, então dar aula para o aluno é muito interessante. (DE2)

O trabalho do enfermeiro docente é cercado de satisfação e prazer graças a sua relação com os alunos e o compromisso com a formação e aprendizado destes, destacando o interesse e reconhecimento que os alunos da área retribuem. A literatura revela que os docentes unem os movimentos de tensão com estratégias adaptativas, o que propicia na sala de aula o prazer de ensinar. ${ }^{10}$ Esse fato que pode ter influenciado o sentimento descrito pelo DE2 nesta pesquisa, ainda que tenha se tratado de um relato isolado.

Por outro lado, os docentes do curso de Medicina descreveram as aulas teóricas não como desgastantes, mas prazerosas. Alguns afirmaram que exercer a atividade docente certamente não é estressante. Assim, pode ser observado nos recortes abaixo:

em sala de aula, eu não considero que tenha algo desgastante, eu acho, é um momento que eu gosto muito, nossa dinâmica de trabalho aqui é muito boa, porque nós somos muitos professores, nós não temos uma sobrecarga de aulas teóricas [...], então eu não acho que isso seja um desgaste. (DM3)

se eu tivesse só a atividade docente certamente eu não apresentaria sobrecarga de trabalho. Não existe desgaste quando se está direto em sala de aula. (DM11)

Dentre os fatores que corroboram com essa satisfação está o reconhecimento dos alunos, a ligação que o professor forma com cada turma e o fato de atuarem juntos na assistência ao paciente.

Assim, a cooperação do corpo discente, a confiança, o reconhecimento, a sensação de ajudar a sociedade, a evolução do aluno durante o curso e a participação na formação de novos profissionais são componentes importantes na construção dos sentimentos de prazer e satisfação na docência universitária em ciências da saúde. Outra variável importante é o nível de satisfação com o próprio trabalho ${ }^{10}$ 


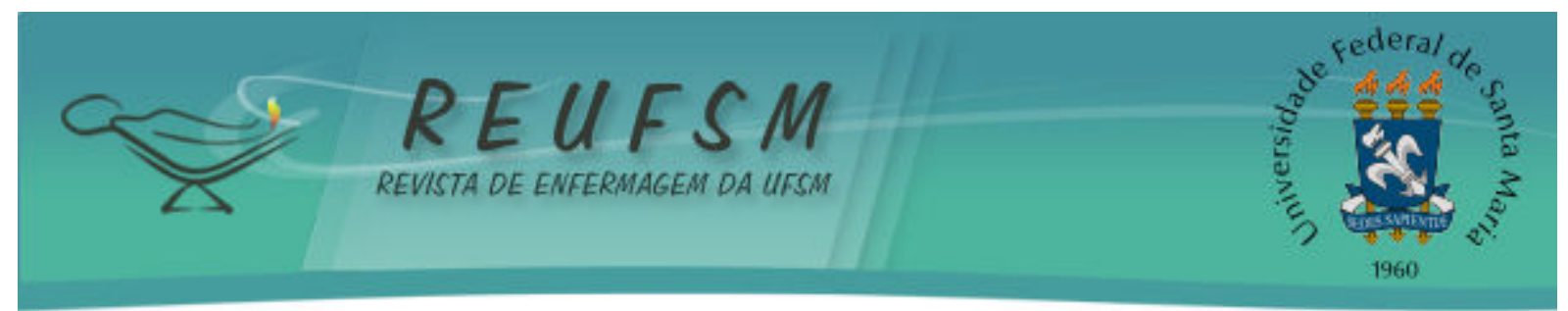

De acordo com vários professores entrevistados, parte das aulas para os estudantes do curso de Medicina são realizadas aliando teoria e prática em pequenos grupos acompanhados pelos docentes em ambulatório, enfermaria, dentre outros, o que permite uma maior dinâmica.

Por outro lado, a teoria ministrada para os estudantes do curso de Enfermagem é realizada, em sua maioria, de forma expositiva e dialogada em sala de aula com toda a turma, para só depois, separá-los em grupos menores que realizarão a prática em instituições prestadoras de serviços de saúde.

Deste modo, a relação estresse - aulas teóricas foi frequentemente observada nas falas dos docentes de Enfermagem, que citam como fatores estressantes as conversas paralelas, ensinar em meio ao barulho, interrupções, entre outros, referenciados por estes nas falas:

os alunos cada vez mais se envolvendo com múltiplas coisas, a impressão que dá é que muitos não estão ali presentes, só o corpo, mas a mente não está presente, a gente nota no decorrer da aula as múltiplas saídas, interrupções, [...] alunos que aparentemente não estão acompanhando o desenvolver da aula. Todos esses fatores acabam interferindo bastante no rendimento em sala de aula e isso me angustia muito. (DE3)

é estressante na sala de aula quando a gente identifica o aluno que não quer aprender. (DE4)

Já os docentes de Medicina consideraram estressante o trabalho com pedagogias diferenciadas, necessitando desprender tempo no planejamento e no preparo das aulas para torná-las mais dinâmicas e interessantes, ao passo que alguns alunos não participam, não demonstram interesse ou a desdenham, chegando a dormir em sala, o que acaba tornando-se desestimulante. Aliado a estes, o uso de aparelhos tecnológicos, conversas paralelas em classe e a falta de respeito foram frequentemente citados, a exemplo dos seguintes recortes:

[estressante] É um aluno abrir um iPad ou um computador e ficar assistindo sei lá o que e não dar atenção nenhuma para o que eu estou falando, isso me irrita. O aluno vai lá para trás para conversar ou dormir, mas o que mais me irrita é ficar brincando no computador. (DM2)

é a falta de interesse do aluno em sala de aula, porque afinal, nós desprendemos tempo em preparar uma aula, em torná-la interessante, em fazer com que o aluno se interesse, participe, questione. Então aquele aluno que apresenta desinteresse, que dorme em sala de aula, que desdém ou que apenas questiona para desafiar o professor, acaba sendo desestimulante. (DM11)

Outro fator colaborador para o desgaste citado pelos docentes de Medicina foi o fato de necessitar repetir todo o conteúdo para os diversos grupos de alunos que passam por cada professor em forma de rodízio de aulas, o que foi mencionado por alguns como um trabalho mecânico e cansativo. 


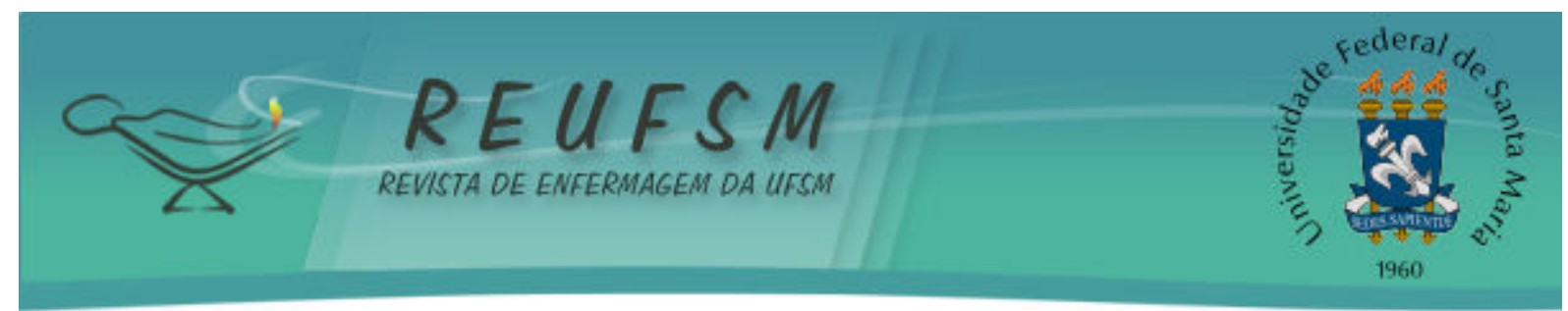

Correspondente ao trazido pela literatura e, também, mencionado nesta pesquisa, são as cargas horárias elevadas e instáveis, a desvalorização do papel do docente e a quantidade de alunos. ${ }^{10-12}$ Comum a ambos os cursos, também, foi a reação diante dos estressores em sala de aula. Os docentes revelaram que, em meio às contradições apresentadas em classe, chamam atenção dos alunos, algumas vezes de forma séria, outras de maneira descontraída, mas que lidam com os problemas de forma tranquila.

\section{A realidade do serviço enquanto um desafio}

A associação dos serviços de ensino e saúde enquanto desencadeadores e/ou potencializadores do estresse profissional foi algo comum aos professores dos cursos de Enfermagem e Medicina.

Os docentes de Enfermagem consideraram como fatores estressantes: falta de equipamentos e laboratórios adequados e funcionantes; conflitos com a chefia; baixa demanda de atividades em alguns setores; precariedade na saúde; campo de estágio inadequado para o ensino-aprendizado do aluno, sem condições mínimas de insumos, segurança e respeito à pessoa humana; dissonância entre o que é ministrado em aula e o que o serviço impõe, de forma que há uma desconstrução do conhecimento do aluno acerca do que é correto, frente a prática que ocorre de forma inadequada. Isso pode ser observado nos seguintes recortes:

[estressante] Um equipamento não funcionar, ou então você está querendo dar aula e tem barulho no corredor. (DE2)

Nós temos hoje um processo de assistência na nossa prática [...] que na grande maioria dos casos está totalmente fora de um contexto de ensino-aprendizado, primeiro que são hospitais que estão voltados para o ensino, mas não estão preparados para o ensino, em termos estruturais e em termos de capacitação de pessoal, [...] acabam produzindo um distanciamento muito grande entre o que nós estudamos na academia e isso é muito ruim para o aluno. (DE3)

Não distante desta realidade, os docentes do curso de Medicina trazem como estressante: a falta de estrutura da rede de saúde e dos laboratórios na universidade; processos políticos e burocráticos; campo inadequado para aprendizado do aluno; marcação excessiva de pacientes para o docente-médico, o que acaba comprometendo o usuário e ao aluno, uma vez que o professor necessita realizar um atendimento mais rápido, o que implica em não explicá-lo de maneira adequada para o discente, como observado nas falas a seguir:

0 mais estressante é você ver o paciente e, poder fazer muito pouco por ele, porque a estrutura não permite que a gente faça, tanto a universidade quanto o Estado. (DM5)

O objetivo é ensinar, o objetivo não é você chegar e ficar atendendo dez, vinte pacientes, pra isso você tem o técnico administrativo, médico, que está lá pra fazer esse serviço. (DM7) 


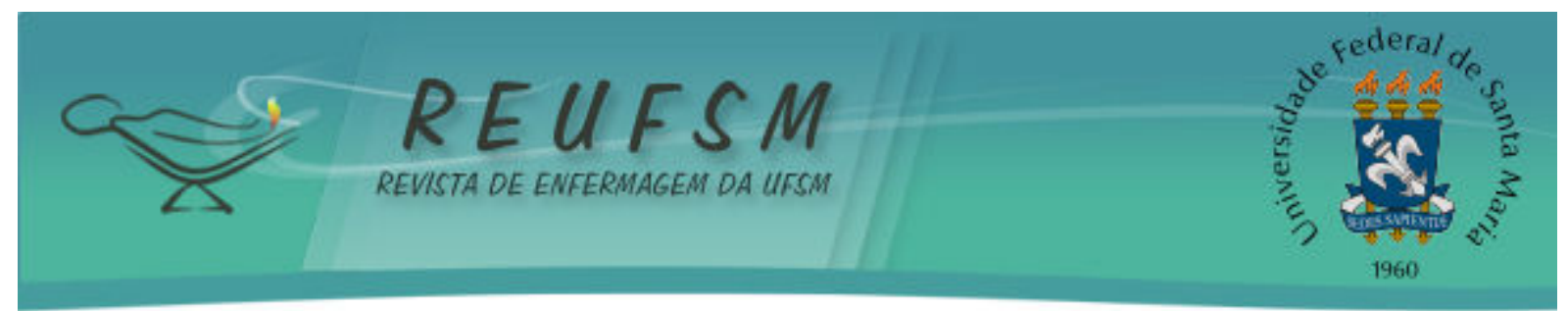

O cenário de atuação destes profissionais apresenta uma gama de aspectos complexos e específicos. Por estarem relacionados à saúde pública, convivem com diversos problemas estruturais, como a falta de insumos básicos para a assistência, além da grande demanda de atividade imposta, o desempenho de seus papéis e o papel da instituição frente aos usuários, expondo-os constantemente a situações que podem ser avaliadas como desgastantes. ${ }^{4,10}$

0 docente encontra-se imerso em um cotidiano de condições insalubres que repercutem no seu trabalho. A literatura afirma que o cotidiano hospitalar é fonte de sofrimento psíquico para os trabalhadores da saúde, e que seu ambiente insalubre afeta toda a equipe. ${ }^{13}$

Vários foram os docentes que relataram um sentimento de impotência por chegarem ao serviço e não poderem ensinar de forma ideal ao aluno ou por comprometer a assistência prestada ao paciente devido à realidade da estrutura disponível nesses serviços. Uma vez que os recursos humanos e materiais são peças fundamentais para o desempenho de suas funções, sua deficiência aumenta o sofrimento psíquico dos docentes e, consequentemente, o risco de desenvolver o estresse laboral.

\section{0 estresse no corpo dos docentes}

Esta categoria abordará os reflexos físicos e psicológicos do estresse e sua repercussão em nível individual e organizacional.

\section{Reflexos físicos do estresse}

Para os docentes de Enfermagem, o desgaste físico está, principalmente, relacionado: às diferentes atividades exercidas no decorrer de um dia de trabalho; às caminhadas necessárias nas visitas domiciliares quando em aulas práticas na Atenção Básica à Saúde; aos atendimentos a pacientes no campo prático que, normalmente, exigem um período do dia completo; passar muito tempo em pé durante as aulas ou em campo prático com alunos representado pelas falas a seguir:

eu acompanho cada dia um aluno diferente, hoje eu vou com um, amanhã eu vou com outro, então esse é o maior o desgaste físico, durante as caminhadas nas visitas. (DE1)

o desgaste físico, o cansaço físico é muito intenso. Uma manhã inteira em atendimento, em relação à prática. (DE4)

Além desse desgaste, alguns relataram já apresentar, inclusive, doenças e complicações como, por exemplo, insuficiência vascular, dor, cansaço e edemas, possivelmente associados à rotina de trabalho.

0 alvo principal das pressões relacionadas ao trabalho tende a ser o corpo do profissional, ocasionando envelhecimento, desgaste e adoecimento. ${ }^{11}$ Tais sintomas podem se apresentar por meio de: aumento da pressão arterial; dores no corpo; mudanças de humor; desumanização; ansiedade; depressão; aumento do consumo de bebidas alcoólicas; problemas cardíacos e gastrointestinais; esgotamento; queda na produtividade; absenteísmo; rotatividade no serviço; dificuldade nas relações profissionais; dentre outros. ${ }^{4,5,10}$

Aos professores de medicina esse mesmo desgaste não foi descrito como resultante das aulas, mas, principalmente, associado aos plantões, e ainda assim, foram poucas as 


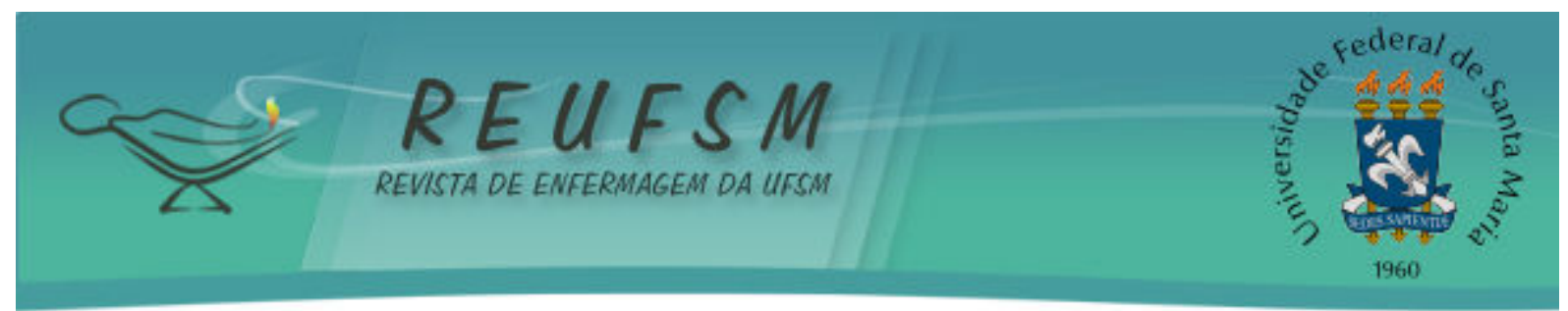

referências ao cansaço físico. Estes referiram taquicardia, hipertensão, pré-diabetes, aumento de colesterol e sobrepeso. Segue os recortes como representativos:

termino, saio sexta-feira do plantão, só o milho da pipoca [risos]. (DM8)

por vezes eu acordo com taquicardia, tive insônia, então isso certamente está relacionado à sobrecarga de trabalho. (DM11)

Seja com relação às aulas, a prática com alunos, ou até mesmo os plantões, os docentes de ambos os cursos afirmaram reconhecer os diversos efeitos físicos decorrentes do estresse de seus corpos, muitas vezes, os impedindo de realizar suas atividades de forma satisfatória. Soma-se a essa carga de funções docentes, os ambientes inadequados onde ocorrem as aulas práticas e os estágios supervisionados, que são atividades descritas como as mais estressantes pelos docentes.

Em meio aos estressores, faz-se necessário uma maior atenção à saúde destes profissionais, uma vez que a efetividade de seu trabalho depende de seu bem-estar e reflete diretamente no ensino dos discentes e na qualidade de vida da população atendida pelos mesmos. ${ }^{6,11}$ Estes sintomas podem desencadear em absenteísmo e afastamento do trabalho por parte do docente. ${ }^{10,12}$ Estudo $^{6}$ indica que os professores com carga máxima, com funções múltiplas e que sentem sua vida pessoal atingida pelo trabalho, já pensaram em mudar de profissão e já se afastaram do trabalho por motivos de saúde.

\section{Desgaste emocional e responsabilidade profissional}

Apesar da relação importante entre o desgaste físico e o estresse laboral, outro fator apresentado como relevante e, muitas vezes, como o principal, foi o estresse psicológico.

Dentre os docentes de Enfermagem destacou-se: a falta de habilidade dos alunos; a responsabilidade com a assistência adequada ao paciente ao mesmo tempo em que orienta e ensina o aluno nos campos de prática; a alta demanda de atividades e procedimentos; a grande quantidade de alunos por grupo em alguns campos de estágio; e lidar com a dor e sofrimento dos pacientes, a exemplo dos recortes seguintes:

[...] tem essa implicação de ser o aluno iniciante, que requer muita atenção, muita responsabilidade, que precisa de um apoio, de segurar na mão mesmo, o que gera um desgaste físico e emocional, pois necessita de uma atenção redobrada, em função de evitar situações de risco tanto para o paciente como também para o aluno. (DE4)

existe o desgaste emocional também, porque a gente está lidando com vidas, com pessoas em situações de risco, em sofrimento, [...]não é fácil lidar com a dor e o sofrimento, então é uma coisa que suga as energias [...] acontece de terminar uma manhã de estágio e não ter condições para ter uma tarde de trabalho produtiva. (DE4)

A literatura ${ }^{4}$ evidencia que as categorias profissionais de Enfermagem e Medicina são as que possuem maior índice de estresse dentre os profissionais da área da saúde, juntamente com a categoria de Serviço social. O trabalho do profissional em saúde é 


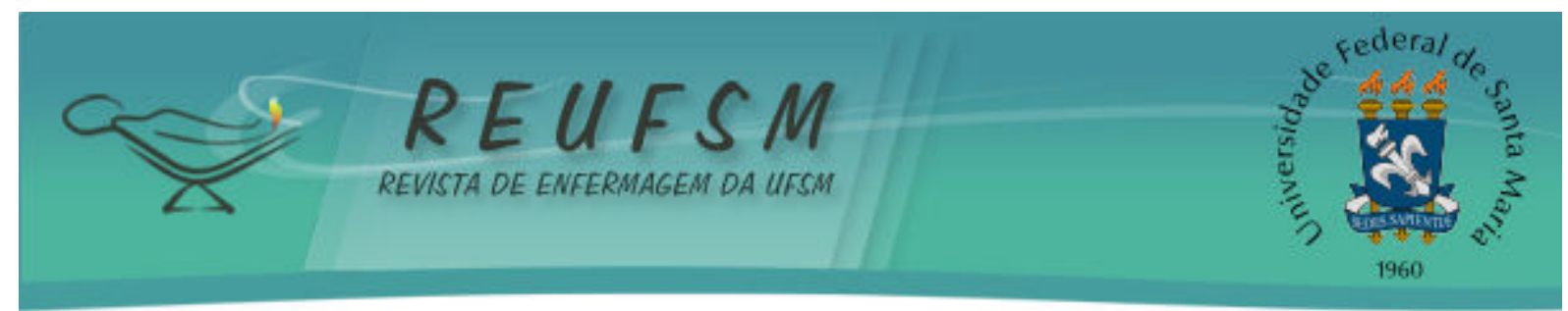

voltado inteiramente ao cuidado do usuário, estando próximo durante o sofrimento, causando desgaste tanto mental quanto físico.

Quanto aos docentes de Medicina, relataram como desgaste emocional, também, a responsabilidade com o aprendizado dos alunos junto à prática, a falta de habilidade destes e a quantidade de atividades que precisam ser realizadas pelo professor, além do grande número de pacientes por docente, a qualidade da assistência prestada, a relação com os pacientes e o óbito, a exemplo das falas a seguir:

então eu chego um caco, cansada, eu não produzo bem à noite e o dia pra mim é pequeno, e tem outras coisas, outras obrigações que eu tenho que dar conta. (DM12)

esses ambulatórios normalmente são um pouco desgastantes, que a gente acaba tendo um número grande de pacientes e a função de docente necessita de um tempo para explicar bem os casos para todos os alunos. (DM10)

Dentre as complicações psicológicas apresentadas pelos docentes de medicina em decorrência do exercício profissional estão: insônia, transtorno de ansiedade e até mesmo depressão.

Um estudo ${ }^{4}$ mostrou que a incidência do estresse foi alta entre aqueles que associavam trabalho ambulatorial e cargos de chefia, ao passo que se concluiu que ao praticar a assistência direta ao paciente e o contato com o sofrimento destes, 0 profissional se torna mais vulnerável, o que chama atenção para o desenvolvimento de outras doenças.

\section{CONCLUSÃO}

A partir deste estudo, foi possível conhecer a percepção dos docentes dos cursos de Enfermagem e Medicina da UFRN em relação aos estressores do seu cotidiano de atuação. Estes referem-se a aspectos relacionados a sala de aula e ao sistema de saúde e repercutem na forma de desgaste físico e emocional desses docentes. No entanto, alguns momentos em sala de aula são percebidos pelos docentes como um ato de realização profissional.

Como limitação, destaca-se que o estudo reflete uma única realidade investigada, o que pode representar aproximações ou distanciamentos de outras realidades semelhantes. Cabe destacar que, em meio a tantos estressores, faz-se necessário cuidar da saúde física e mental destes docentes, a fim de evitar impactos, tanto individuais, quanto organizacionais. Espera-se suscitar novas reflexões acerca destes fatores para que cada profissional os identifique em seu cotidiano de trabalho e, assim, defina um curso de ação como forma de minimizar o estresse, visando qualidade de vida em seu ambiente profissional.

\section{REFERÊNCIAS}

1. Smeltzer SC, Bare BG, Hinkle JL, Cheever KH. Brunner \& Suddarth. Tratado de enfermagem médico-cirúrgica. Rio de Janeiro: Guanabara Koogan; 2009.

2. Assunção RM, Castro PF. Relação entre estresse laboral e personalidade entre profissionais da área de saúde. Rev saúde. 2011;5(2):4-16. 


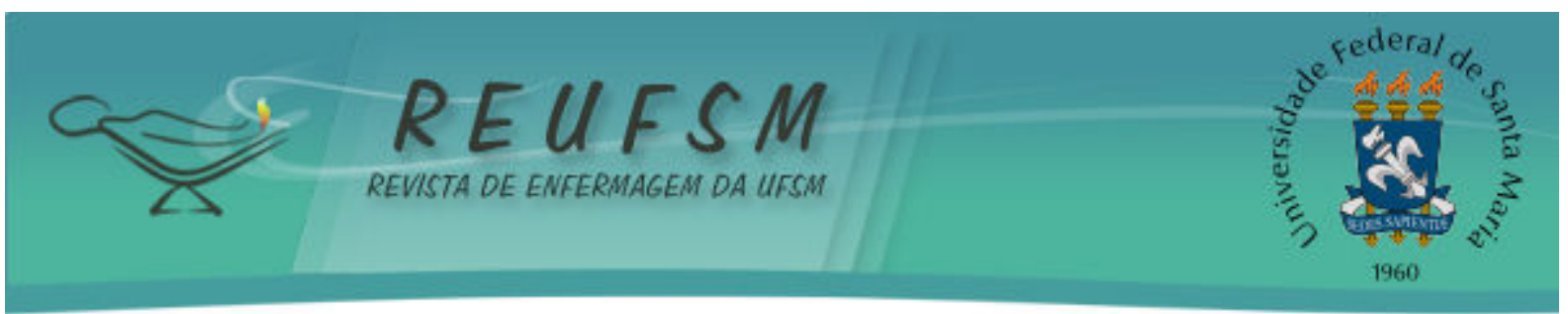

3. Reis ALPP, Fernandes SRP, Gomes AF. Estresse e fatores psicossociais. Psicol Ciênc Prof [Internet]. 2010 [acesso em 2014 dez 20];30(4):712-25. Disponível em: http://www.scielo.br/pdf/pcp/v30n4/v30n4a04.pdf.

4. Schmidt DRC, Dantas RAS, Marziale MHP, Laus AM. Estresse ocupacional entre profissionais de enfermagem do bloco cirúrgico. Texto \& Contexto Enferm [Internet]. 2009 [acesso em 2014 dez 12]; 18(2):330-7. Disponível em: http://www.scielo.br/pdf/tce/v18n2/17.pdf.

5. Zorkot L. Estresse ocupacional e a atividade docente. Rev Conexão Ciência. 2011;6(2):56-60.

6. Souza ISN, Silva FJ, Gomes RLV, Frazão IS. Situações estressantes de trabalho dos enfermeiros de um hospital escola. Rev Enferm UFSM [Internet]. 2013 [acesso em 2014 dez 20];3(2):287-95. Disponível em: http://cascavel.ufsm.br/revistas/ojs2.2.2/index.php/reufsm/article/view/8322/pdf.

7. Fontanella BJB, Ricas J, Turato ER. Amostragem por saturação em pesquisas qualitativas em saúde: contribuições teóricas. Cad Saúde Pública [Internet]. 2008 [acesso em 2016 jan 18];24(1):17-27. Disponível em: http://www.scielo.br/pdf/csp/v24n1/02.pdf.

8. Brasil. Ministério da Saúde. Resolução CNS n466, de 12 de dezembro de 2012. Diretrizes e normas reguladoras de pesquisas envolvendo seres humanos. Brasília: Ministério da Saúde; 2012.

9. Mozzato AR, Grzybovski D. Documentos e debates: análise de conteúdo como técnica de análise de dados qualitativos no campo da administração: potencial e desafios. RAC (Curitiba)[Internet]. 2011 [acesso em 2014 nov 28];15(4):731-47. Disponível em: http://www.scielo.br/pdf/rac/v15n4/a10v15n4.pdf.

10. Oliveira MGD, Cardoso CL. Stress e trabalho docente na área de saúde. Estud Psicol (Campinas) [Internet]. 2011 [acesso em 2016 fev 3];28(2):135-41. Disponível em: http://www.scielo.br/pdf/estpsi/v28n2/01.pdf.

11. Tavares JP, Magnago TSBS, Beck CLC, Silva RM, Prestes FC, Lautert L. Prevalência de distúrbios psíquicos menores em enfermeiros docentes. Esc Anna Nery Rev Enferm [Internet]. 2014 [acesso em 2016 fev 3];18(3):407-14. Disponível em: http://www.revistaenfermagem.eean.edu.br/detalhe_artigo.asp?id=1213.

12. Andrade PS, Cardoso TAO. Prazer e dor na docência: revisão bibliográfica sobre a Síndrome de Burnout. Saúde Soc [Internet]. 2012 [acesso em 2016 fev 3];21(1):129-40. Disponível em: http://www.scielo.br/pdf/sausoc/v21n1/13.pdf.

13. Ferreira RC, Silveira AP, Sá MAB, Feres SBL, Souza JGS, Martins AMEBL. Transtorno mental e estressores no trabalho de professores universitários da área da saúde. Trab Educ Saúde [Internet]. 2015 [acesso em 2015 nov 3];13(1):135-55. Disponível em: http://www.scielo.br/pdf/tes/v13s1/1981-7746-tes-13-s1-0135.pdf.

Data de recebimento: $28 / 02 / 2015$

Data de aceite: 05/02/2016

Contato do autor responsável: Natally Pereira da Silva

Endereço postal: Universidade Federal do Rio Grande do Norte, Av. Senador Salgado Filho, 3000 Escola de Saúde da UFRN. Sala 06. Natal-RN, Brasil. CEP 59078-970

E-mail: natally_pereira_23@hotmail.com 